Kohl: a Journal for Body and Gender Research

Vol. 5, No. 2 (Summer 2019)

\title{
Rematerialization, Art, and Affective Economies
}

\author{
Azza Zein
}

\begin{abstract}
:
The paper highlights artworks that engage with materials to comment on the dematerialization of the economy and the invisibility of labour. The emphasis is on artworks which disturb these conditions through a process of rematerialization, defined as "attending to materials." How to revalue what has been dematerialized, devalued, or deemed invisible? To revalue invisible labour is to find a material that can engage with the affective relation surrounding labour and space, a material that can experience the invisibility rather than represent it. By correspondences of materials, actions and the body, the artworks counter abstraction and standardized value. One can identify across diverse contemporary artworks parallel forms of rematerialization through tasks. Tasks are free from the hegemony in the binary of work vs. leisure and productive notions of land and labour. The geographically dispersed artistic examples present a possible process of revaluation rather than mere critique of value. These examples are compared against twentieth century artworks considered critique of standardized value. With the help of affect theories, the paper argues that such rematerialization through care and attention may offer a "reparative" process that posits an alternative to exposing economic structures.
\end{abstract}


One evening in 1987, my father came back home asking how many Lebanese coins we had. We brought our piggy-box savings and went fishing for more coins in diverse pockets around our small apartment. It all felt like a funny game. After collecting the coins inside a metallic bronze box, he explained: the Lebanese pound had just been dramatically devalued. "We are sitting in front of history," he uttered. Between his sense of grand exaggeration of political events and his sense of humour, we didn't understand much but happily believed him. That night as kids, our game turned into exchanging different types of coins instead of marbles.

It was my first experience of how coins turn from a medium of exchange to an artefact or maybe a material to play with. Perhaps here lies the seed of my interest in both economics and fine arts. What exactly happened to the coins that night? Any standard economic textbook would say money is a medium of exchange, a store of value, and a unit of account. Due to inflationary pressure and the central bank devaluation, the coins lost these three functions and regained their material existence as objects in our environment. "Lost" is often the verb used by economic professionals; I would prefer to say those coins were freed from their role to count and account for economic standardized value. Through the act of play, the coins took a new role. By tracing this shift and the relation between the act of playing and the object, one can understand both the affective space around the object and the bodies.

This memory paves the way to a current economic condition: the conceptual disconnection between the material encounter with objects and resources, and the way economics as a mainstream discipline represents it. The dematerialization process in capitalism is tied to a restricted understanding of labour and land as productive resources. The memory underlines the role of play in rematerializing an object that has lost its economic value. To avoid general terms about the economy, I would like to focus on some features of the economic system: abstraction, standardization, quantification, and productive labour and land.

\section{Dematerialization and abstraction}

Abstraction of value is a process by which an object, a person, or a resource is reduced to its market exchange value disregarding other social values. To be able to be reduced to its market value, there needs to be a standard to compare it with. Such standard needs to be quantified. Exchange value of the object in the market may include emotional relation such as fetishism for the good or stock that may drive up or down its price. Any other emotional values that are non-marketable, such as personal or collective association around the material, become irrelevant and often invisible. It is to these indeterminate set of non-marketable emotional values that I refer to when I talk about affective space. Through abstraction, economic dematerialization becomes a detachment of value from life and social history of its materials due to an emphasis on productive or efficient outcomes. This can happen to an object, land, or a person. For an object, the dematerialization occurs when it is only perceived as a commodity in the market (like a commercial art object) or a medium of exchange (like the devalued coins). For land, the dematerialization occurs through contracts that can move the ownership of the land for productive goals only, independently from its ancestral history or ecological concerns. Mainstream media and economics 
divide labour between skilled vs. unskilled, and migrants between refugees and economic migrants, creating abstract hierarchies among those who are on the move. Labour that is less valued becomes invisible. Those hierarchies reinforce capitalism as a system tied with land, which becomes an economic resource worthy of productive labour only. The erased ties to the land also erase the other non-productive tasks culturally associated to a place. ${ }^{1}$ In the nineteenth century, examples of such dematerialization can be traced in the history of land ownership contracts. ${ }^{2}$ Financial markets are another example of the disconnection of value from the material production as well as labour time. ${ }^{3}$

The notion of dematerialization of the art object is slightly different. Since the 1960s and 1970s, many artists have decoupled the notion of artistic concepts from the art object and its materiality through conceptual art and performance works. In 1972, Lucy Lippard and John Chandler explain the term as follows:

The visual arts at the moment seem to hover at a crossroad that may well turn out to be two roads to one place, though they appear to have come from two sources: art as idea and art as action. In the first case, matter is denied, as sensation has been converted into concept; in the second case, matter has been transformed into energy and time-motion. (Lippard 1973)

The dematerialization of the art object came as a rejection of the fetishized singular art object in the market. Yet it seems a condition that mimics the contemporary tendency of markets to become more and more abstract and dematerialized. How can there be a process of rematerialization in art in the face of a "dematerialized" economy?

To the violence of invisibility, art may offer an alternative: revaluation through rematerialization. I use the term rematerialization or material correspondence interchangeably. I am defining material correspondence as an artistic process that "attends" to materials. ${ }^{4}$ I would like to argue that creating correspondence between the artists' embodied gestures and the properties of materials can resist economic dematerialization. Attending is caring. Tasks include care and rituals among all living things, not only humans. They are performed. They escape the binary of work vs. leisure. To revalue invisible tasks of caring, one may attend to the material associated with it.

The paper emphasizes artworks that can reimagine forms of alternative economies through material and bodily encounters, by subtle disturbance of current economic conditions such as abstraction and standardization. The choice of artworks is not to identify an overarching movement in art history. They have inspired my practice-led research and my interest to identify materials that correspond and counter these conditions in my studio. In particular, I look at rematerialization in works by Cecilia Vicuña's

\footnotetext{
${ }^{1}$ One could discuss modernity in this way but that is a different project. For the scope of the paper, I am interested in how artists can rematerialize the invisible tasks or labour without necessarily exposing.

${ }^{2}$ The artist and writer Rachel O'Reilly (2018) clarifies how the same legal framework of shipped property to land property led to a more efficient transfers. In the $19^{\text {th }}$ century, titles and contracts were dematerialised through a "threefold principle of mirror, curtain and indemnity" process.

${ }^{3}$ See the different types of abstraction in the financial economy and the link with symbolism in language in chapter 2 of Franco 'Bifo' Berardi, Semiotext(e) Intervention Series (2012).

${ }^{4}$ The term "attending to materials" is borrowed from the anthropologist Tim Ingold (2015).
} 
Symbiosis, Ritual Battle (2015), Mira Gojak's Distant measures (2016), Kate Newby's A rock in the pocket (2018), and Alfonso Cuarón's Roma (2018). The examples offer a possible process of revaluation rather than a mere critique of value. The choice of geographically and aesthetically dispersed examples does not undermine the particularity of each artistic process. It is meant to show some common conceptual features of rematerialization. These examples are compared against the tropes of some twentieth century artworks considered critique of standardised value. The paper highlights these in parallel with personal narratives in relation to affective spaces precisely to revalue the invisible tasks, not only within my own domestic space, but also within the reading of such artworks.

\section{Writing as abstract record-keeping}

Early forms of dematerialization from concrete counting to abstract counting could offer insights into how writing as abstract record keeping has emerged through a dematerialized process. One could conjecture that national economies as understood today are founded on abilities to measure (count), record (written and other visual forms), and make policy (statecraft). In How Writing Came About (1996), the archaeologist Denise Schmandt-Besserat explains that counting is at the origin of writing. Until the fourth millenium B.C., small tokens were used to account for how much food and animals a household had in storage. The token operated as one-to one correspondence. In other words, if someone had six bags of grain they would create six identical clay tokens and place them in a clay envelope. This process of oneto-one correspondence is a direct mapping between the counted stock and the tokens. These Mesopotamian tokens would have counted commodities. Schmandt-Besserat makes the distinction between computing and accounting: "Computing consists of making calculations. Accounting, on the other hand entails keeping entries and withdrawals of commodities" (1996, p.103). The neolithic system was incapable of dealing with large quantities and varieties of goods. When stored into the envelope, the tokens left marks onto the wet clay. Eventually, the marks of the token without the tokens became sufficient as a sign of accounting: this marked the beginning of writing in Mesopotamia.

One-to-one correspondence and concrete counting are interesting historical moments. They allow us to imagine how concrete phenomena through mapping are at the inception of the making of an artefact like the token and its relation to the idea of state. The early state emerged in wetlands where grain agriculture became possible. The historian James Scott links this phenomena to the idea that the surplus, associated with grain agriculture, generated the possibility of a social class being able to rule over others. For the state to have emerged, the grain is of importance because it was visible, above the ground, and countable. For taxation purposes, this was an ideal crop to measure. ${ }^{5}$ Coerced or "domesticated" labour was captured and forced to produce beyond their needs. ${ }^{6}$

In the early states, it was necessary to take stock and to count. Paraphrasing Schmandt-Besserat, counting takes three forms: one-to-one correspondence, concrete counting, and abstract counting. The counting we know today is abstract counting and it seems to have emerged as a more efficient method

\footnotetext{
5 "The key to the nexus between grains and state lies, I believe, in the fact that only the cereal grains can serve as a basis for taxation: visible, divisible, assessable, storable, transportable, and 'rationable'" (Scott 2017, p.129). ${ }^{6}$ See chapter 5 of Scott's Against the Grain: A Deep History of the Earliest States (2017).
} 
to account for the variety of data. ${ }^{7}$ In other words this historical move to abstraction in thinking can be immediately linked to an initial process of dematerialization.

What do we mean by dematerialization in this case? First, the writing of numbers became a trace rather than an object. Second the one-to-one correspondence suggests a literal relation between the stock and the tokens. A technical word in mathematics for this process is cardinality. Cardinality refers to the number of elements in a set. The stock of food in a household and the tokens would presumably have the same cardinality. Third, the dematerialization happens through a form of generalization that counting is not tied to the form and the material qualities of the object.

In other words, dematerialization is the disconnection and abstraction from the physical world to account efficiently for data and to make the transfer and circulation of information quicker.

In response to this dematerialised condition of the economy, the following section defines rematerialization as an artistic process that revalues materials through correspondence and care. To rematerialize is to reconnect with how materials act and perform and how the human body can facilitate these actions. It is to create correspondence between the material properties and the body. To rematerialize invisible tasks is to identify the corresponding materials that have endured similar invisibility and create the commensurate gestures and actions that can make them visible.

\section{Rematerialization as affect, revaluation as rematerialization}

In 2016, in Melbourne, the work of Nicholas Mangan at Monash University Museum of Art revived my memory of the devaluation night. The large prints of the Rai stones, a currency from the Micronesian island Yap, seemed heavy, incongruent with current forms of currencies that circulate rapidly. In the show, there was a room in the basement with a bitcoin machine. The photographs presented the Yap currency as tied to the landscape in contrast to Mangan's bitcoin-mining machine. ${ }^{8}$ Both types of currency had a relation with the physical world but the bitcoin seemed dematerialised from the landscape. The virtual mining of the bitcoin relied on decoding a blockchain. In an interview, Mangan explains that the Rai reflects a society that is trustful of each other and the bitcoin a distrustful one. ${ }^{9}$ One is left with the general question: How does the materiality of an economy reflect its social life?

Note that mistrust and processes of coding and decoding, inherent to a blockchain technology of the bitcoin, can parallel the "hermeneutics of suspicion" and "paranoid" critique, as discussed by the affect

\footnotetext{
7 Concrete counting differs across different cultures and it utilizes a variety of the number-words sets to count different objects. The word or symbol simultaneously refers to both a number and the type of the counted object. So for example words used to count long objects are distinct from those for round objects.

See Schmandt-Besserat, p.112.

8 See Nicholas Mangan et al. (2016) and Nicholas Mangan (2017).

${ }^{9}$ Mangan explains: "I find bitcoin's removal of the need for trust through its block chain technology very telling. In a way this antisocial technology befits our social fabric-it is appropriate to the level of mistrust in society" (2016, p.231).
} 
theorist Eve Sedgwick. ${ }^{10}$ The paranoid reading is a "strong theory of negative affects" that "places its faith in exposure" (Sedgwick 2003, p.124). For Sedgwick, the multiple possibilities of a "reparative reading" are proposed in contrast to the limits of "paranoid" critical reading. In the context of art and the current economic conditions, instead of a "weak proposition," the artwork may indirectly comment on the economic conditions by avoiding a didactic position. This seems necessary in a world where the economy of information is driven by negative affects of fear and precarity. ${ }^{11}$ The devaluation night remains a pleasant memory despite its tragic consequence. In the memory of play as kids, we reclaimed a role for the coins independent of their economic value. My parents could have been "paranoid" or worried; instead, we were reminded of the coins' artefact value and the potential of play.

I am born to a Syrian mother and a Lebanese father. I grew up in Beirut and spent my childhood escaping with my family to Damascus. Decades later I travelled to study and work in the U.S., then moved to Melbourne, Australia, with my partner from India. How to rematerialize my floating migrant body among multiple places? The concrete touch and gesture onto materials in the studio makes visible my distant relation to all the places I inhabit or inhabited.

To escape a rigid structural academic research without compromising my interest in forming an academic inquiry, my approach to writing is to create a drift of correspondence between the conditions of the current economic system and certain artworks that attest to material and formal responses to these conditions. ${ }^{12}$ To comment on the economic system, I avoid a "paranoid position" in the following way: first, I focus on artworks that do not have an explicitly-visual political position. Second, the artworks do not fall under one overarching artistic style. I qualify their process as "reparative" since it generates a positive affective experience rather than a cold conceptual stance. Third, the paper highlights the concept of material correspondence, or "attending to materials" as an affective process to navigate through these artworks along with personal narrative.

In terms of form, the paper follows the relational method between image, material, and text in the video Symbiosis, Ritual Battle (2015) by the Chilean artist Cecilia Vicuña. The collaboration video between Cecilia Vicuña and the conservation ecologist Meredith Root-Bernstein asks us to imagine the formal visual qualities of forces such as competition, reciprocity, and symbiosis by playing with simple tasks/gestures on the video plane, using horizontal and spiral movements. The video emphasizes kinaesthetic forces generated around the objects rather than each object separately. The use of text is not didactic but emphasizes both human impacts and a relation between materials. The form that the materials take corresponds to the words.

There are three key frames: Symbiosis, Competition, and Reciprocity. The titles are overlaid as text on top of the image. The screen shows objects made of multiple found materials. Among the materials are

\footnotetext{
10 In relation to queer and feminist literature, Sedgwick's Touching feeling (2003, p.124) explains how paranoid critique relies fundamentally on exposing the systemic practices of exclusion by being "reductive" and "mimetic" and may end up "unintentionally" making it less possible to challenge the political status quo.

${ }^{11}$ On economies of fear, see Sara Ahmed's "Affective Economies" (2004). On financial markets dereferentialization and labour market precarity, see Berardi (2012).

${ }^{12}$ Rather than a museological approach that presents an exhaustive summary of the topic, I am more interested in work that I have seen and experienced in cinema, galleries, or in my studio.
} 
corks, fish cans, lines, threads, wires, matchstick, brush, found plastic, felt, and nails. The first one entitled Symbiosis is immediately followed by the words "Tinkuy: a ritual battle." The word symbiosis on the screen corresponds to the action of the hand onto the materials: it is a mixture of hand performance and a resulting unexpected movement of the materials in relation to each other. The text "a new creature emerges" confirms the organic possibilities in the inorganic assemblage. The objects taken out of the tin can are ready for the battle. The human hand is driving these micro-forces playfully, but not necessarily with mastery. The word Reciprocity is matched with spiral entangling around two metal pieces looking like an abstract figure.

Competition is not visualised against reciprocity; rather, both are intertwined as part of a ritualistic cycle. We are not alerted about a fearful condition or a critical reading of what competition is, but rather to the possibility that this affective ecology could suggest a shift in our understanding of these words. We are not forced into a critique of competition but rather a revisualization of it as a force among many other forces and thus a revaluation of these forces. The three words and the found materials all correspond to a system of exchange and circulation.

Can rematerialization be a form of caring? How can we revalue care? Can caring be a site of resistance and knowledge? If rematerialization is a form of care and repurposing of materials by the bodies that enacted this care, can it be a kind of an epistemological practice? One that revisualizes alternative economies?

\section{Rematerialization as correspondence}

In the following I would like to argue that rematerialization as correspondence is a "reparative" process, as it is not bound to one general method. I will discuss two distinct contemporary artworks from artists whose works are in tune to materials: Mira Gojak's Distant Measures (2016) and Kate Newby's A Rock in this pocket (2018). I will compare their process of revaluation to two canonical works that critique value: Carle Andre's Equivalent (1963) and Marcel Duchamp's Stoppage series (1913).

The artist Mira Gojak's work Distant measures (2016) is an example of rematerialization taking the form of correspondence. She chooses the wrapping of blue acrylic yarn to map the distance between the earth and the blue sky (Green 2016). This is not a quantified measure. It is a form of bodily accounting of all the possible hand gestures of wrapping the yarn. It reflects concrete counting in the sense that the gesture is commensurate to the wool-like material. The properties of the thread is not driving the work. It is the conjunction of the properties and the process of correspondence that renders the work an active resistance to quantification. I chose the word commensurate not in the meaning of "reducible to one measure," but in the sense of weaving its broken components com-and mensurate: to measure together. ${ }^{13}$ Thus, Distant measures is a proposal to rematerialize by measuring together, with the material and with the hand rather than outside and away from these works. The action is not in the gallery nor is the body. The length of the thread wrapping is accounting for the distance; the suggested action of the missing body is counting time. The thread is hugging the metal in a cocoon form. Unlike winding a thread

${ }^{13}$ As per the Online Etymology Dictionary. 
in a standardized industrial process, the thread is instead amassed and spun around the metal, embodying the hand action. The variation of the form each time and its organic distribution in height and width across the space creates a rhythm with the embodied action. It is in this rhythmic display that the repeated action accentuates that the accounting is each time different. The time-space matrix is replaced by the matrix time-material-body.

The concept of quantification relies on the idea that one can have a unit standard. In Stoppages: 3 standard stoppages and Network of stoppages, Marcel Duchamp throws a one meter thread on the ground from one meter height; he traces the resulting undulating line and declares it "a new standard" (Faietti and Wolf 2015). This work is often read as a pseudo-experiment, a parody of the scientific process, by questioning the idea of standardization behind science. ${ }^{14}$ Gojak adopts the seemingly "perfunctory" task of wrapping the thread, which is an inherent feature/action of a yarn. Of course, the action of wrapping is human-driven, but it operates as an engagement with the inherent quality of a thread, unlike the action of dropping it. The thread seems to have succumbed to the natural ritual of spinning like a cocoon, more so than a contemporary industrial process. The artist gives it the chance to borrow the cocooning action embodied in a silk thread. So in comparing the two, Duchamp's Stoppages, while metaphoric, remains structurally elegant and reductive, whereas the action in Gojak's work seems to be "attending to materials."

Another very different work that reflects a process of rematerialization is Kate Newby's installation at the 2018 Sydney Biennale, Equilibrium and engagement. It is also a piece that evokes my memory of the devaluation night. In the site-specific installation $A$ rock in this pocket (2018), there are coins among the diverse materials and inscribed gestures embedded or laid onto 900 bricks. The coins, rocks, and gestures are finding their natural space among the cracks of the brick, or in some cases forcefully claiming it. The subtlety of the small objects doesn't reduce the suggested violence of some of the gestures that intrude into the brick. The work is displayed in a grid form on the ground. The horizontality and the brick material remind me of Carl Andre's Equivalent series; yet, it is a totally different take on value.

Andre's work emphasizes the equivalence of mass reproduction of objects and their loss of individuated gestures. In contrast, Newby's A rock in this pocket modifies each brick with subtle inscriptions. The work may blend with the site but each piece maintains its particularity. The fitting or placement of objects suggests correspondences of contours or forms. There is no standardization in the work but there is equal treatment of materials. The implied gesture of tools and hands mimics perhaps the errant forms that time inflicts on materials. This is not an eroded wall from an ancient civilization or floor mosaic. It has a tentative form of an archaeology of the everyday economy. How do the forms and lines of inscription reflect the brutality of everyday economy? The coins, porcelain pieces, and rocks all fill and fit in a hole or stand provisionally as if waiting to be collected. The objects have no use-value. They are neither taxonomized inside a museum vitrine, nor inside the shelves of a pharmacy. They seem to be waiting. The whole site seems in waiting. Waiting is counting time, in a continuous way. Waiting is slow. Does it look like a segment, with infinite points inside? Maybe the image of the segment is the result of the

\footnotetext{
14 Herbert Molderings (2010) follows the concept of chance in the work of Marcel Duchamp to analyse the contradictory nature of his playful work. He documents the historical knowledge of mathematical theory and painting perspective theory referenced in Duchamp's Stoppage series.
} 
arithmetization of time and space. It is not a segment; it is rather a body with a hunched back looking at the floor and walking back and forth.

Both Mira Gojak's Distant measures and Kate Newby's A rock in this pocket attend to materials in different ways: Gojak through an embodied measure of distance, Newby through a tentative archaeology of the everyday. In each, the body gestures become dissimilar to the one before and the one after, each as a force activating and responding to the material at hand. Both works gravitate towards the ground. Both works' processes speak of some cyclical measure of time and tie such account to the body. While the works do not critique value, they each propose a distinct process of revaluing and accounting. The embodied gestures in these different artworks echoes the playful repurposing of the devalued coins in my memory. This is not rematerialization from virtual space into physical space. Rather, it is about care for materials and care as a relation that can be embodied. The revaluation relies on the body and artistic "labour" time to create the installation. The rematerialization does not end up with an "art object," but rather with an occupation of space. To rematerialize is not to revalue the art object as singular but to emphasize the forces within materials corresponding and interacting with the body or the human gesture.

\section{Dematerialization of the ground}

During the Lebanese civil war, I sat long hours in the backseat of cars, escaping Beirut to Damascus and would try to imagine how far the blue sky was. Yet, the sound and feeling of the bumpy mountainous road always drew me internally to the ground. As a child, the ground was materially diverse and uncertain. There were rugs and carpets: some for decoration and others for prayer. There were carpets hanging from bombed buildings, residue of torn grounds in Beirut's streets. There were carpets on car seats of taxi drivers, whose knowledge of routes and maps was essential to get us safely from Beirut to Damascus. How can one represent the data in this affective space? Should one graph the numbers of taxi drivers along the route per month? Can one model the demand for a particular taxi company because the drivers knew the mountains better and were friendlier and more caring? Could such knowledge help cope with the uncertainties and fragilities of war?

Take for instance a simple tool to represent economic data: the cartesian graph. The graph is not a tracing. It does not operate through correspondence but rather some reductionist relation. A graph is a popular way to represent a snapshot of a set of data. How can one compare the economic graph to any other line? Once one has forced the abstract concept of the zero $x$-axis, the ground is homogenized. Every point in the space can be mapped in reference to it, above, below and on it. In this assumption, the granularity and diversity of the ground that a bare foot may navigate becomes irrelevant and gets erased. 15

At the root of this dematerialization is a process of arithmetization of human behaviour. Explaining Heidegger and Husserl, Bernard Stiegler asserts that "modern technics constitute the Gestell (enframing) of nature and of humanity through calculation" (1998, p.10). What cannot be measured cannot be valued,

${ }^{15}$ See the discussion on land vs. landscape in Tim Ingold's "The Temporality of the Landscape" (1993). 
and thus cannot be appreciated. To measure is founded on some form of standardization. ${ }^{16}$ In fact what mainstream economic models refer to as resources such as land, capital or labour are perceived as quantifiable notions often dealt with in a standardised way.

The experience of a space is intertwined with its diverse materiality. It is through the emotional relation with its materials that we form an affective impression of the space. Many of us have migrated and travelled to seek economic opportunities and escape fragile states. Our relation with land became an unneeded fantasy subordinate to "rational" decisions to move as human labour. To be valued as labour, one had to build skills that can be visibly valued in the globalised market, so valuable that it can overcome market uncertainties. This seemingly personal choice to leave turns out to be a systemic process in migration: the dematerialization of the body from other collective bodies, from a continuous relation with a place, and from the material environment that one cares about. By migrating, I exchanged the uncertainty of the economy for the uncertainty of belonging. In such trajectories one searches for care. The taxi drivers who drove us to Damascus understood that.

The safety associated with the ride required an intertwined relation between the land as a route, the care of the driver for the passenger and for the car. The care is revealed through tasks of cleaning and arranging the interior space of the car with objects from a domestic space: carpets, rosary and home photographs. Today any Uber rating may reduce all this into one number given to the driver. Would that be sufficient to reflect the affective space created through care? How can we delineate this embodied "parallel economy" of contingent routes and knowledge that are constantly changing? I have argued that one form is by reclaiming how materiality with its temporal changes and local qualities can reflect that.

\section{Taskscape vs. productive land and labour}

My memory of Damascus is filled with tactile emotions, love and memories of women gathering at my Amme's home where she would be making embroidered pillows and bags, and fixing or tailoring their clothes. I remember vividly the residues of threads on the floor scattered from the embroidery. The door of the balcony opens and hot air blows a small red thread onto the floor. The thread moves freely and joins a soft dandelions' head. Amme picks the thread gently and lets it roll around her fingers. The curvy coloured cotton threads and dandelions made the walls of this apartment seem softer. Everything seemed softer in this home: the voices, the hugs, the expectations. The attention of my Amme to minutiae from the tiniest thread to the eloping dandelions made her work pleasant and unquantifiable. One could not measure it by the value of her embroidered bags or the input of hours spent. She seemed an extension of her working space which was also her home space. The thread and the dandelions' soft movements trace "what is more than value" in this space (Massumi 2018, T10 Lemme a). "What is more than value" theoretically may seem difficult to determine. In reality it is defined within a context, a space, a particular time. Brian Massumi affirms that "A revaluation of value must contrive to develop this

\footnotetext{
16 Talking about the determinism of the technical object, Stiegler explains: "This tendency to standardization, to the production of more and more integrated types, makes industrialization possible, and not the converse: it is because there is one or another tendency in the process of technical evolution in general that industry can appear, and not because industry appears that there is standardization" (1998, p.72).
} 
connection between value and vitality that is presupposed by the market but disavowed by it" (T10 Lemma c).

There were no dandelions in Beirut.

A process of rematerialization is connected to how the body acts and cares for materials. In this section I turn to frame material correspondence within the concept of Taskscape. "Labour is homogeneous and quantitative," reminds the anthropologist Tim Ingold, referring to productive labour; in contrast, he proposes an "entire ensemble of tasks, in their mutual interlocking" (2015, p.159-160). Given that the global economic system's central anchor is the dichotomy between work and its negation of certain forms of leisure dismissed as laziness, a concept of tasks is more inclusive of activities such as rituals, chatting, regular care of people, objects and nature etc. Animals and insects perform tasks. Embedded in the concept of tasks is a non-hierarchical relation between objects and beings. The concept of tasks includes invisible labour. It seems to be open-ended and frees us from the categorization of quantification and homogeneity. It allows a form of embodiment when considering alternatives to labour and landscape.

The temporality of the taskscape is social, then, not because society provides an external frame against which particular tasks find independent measure, but because people, in the performance of their tasks, also attend to one another. (lbid.)

The work of Francis Alÿs, When faith moves mountains (2002), is often given as an example of "lavish expenditure of energy" and a cooperative economic model. 500 volunteers were given the task of digging the ground and eventually moving a sand dune a few centimetres outside Lima in Peru. In addition to highlighting a cooperative framework against a competitive-efficient model, the work reminds us that capitalism is tied to a particular understanding of land as a resource subjugated to human labour. The land is worked. The land is occupied. In capitalism, it has no agency beyond being a quantifiable resource.

While Alÿs uses a social engagement strategy to present a positive cooperative framework, the Syrian director Omar Amiralay documents a personal history of a land through an emphasis on chatting. In The plate of sardines (1997), he films the ruins of Qunaitira, a Syrian city at the border with Israel/Palestine. It was occupied in 1967 and completely destroyed by Israeli forces upon their withdrawal in 1974. The director's voice narrates how his first childhood memory of Israel and the displacement of his aunt was associated with eating sardines. At the end of the documentary, a woman sits in front of the fence between the Syrian and Israeli lands. She holds a speaker and starts updating her family on the other side about her life. Her concerned voice crosses the border, perpendicular yet invisible to the fence dividing the horizon. This last scene follows the narrator describing how the Israeli army used the electric plough to occupy the Syrian land and to provoke the Syrian army to shoot in 1967. The women's chatting scene acts as a refusal to confine the land to productive economic labour. The director seems to make a statement not just against occupation, but against the alliance of capitalism with nationalism as well. ${ }^{17}$

17 This image can be contrasted to the colonial British army documentary of Palestine in 1946, Palestine Police, where the Arab Bedouin is portrayed as working the land with rudimentary tools in comparison to the advanced agricultural machine of new settlers. 


\section{Rematerializing invisible labour}

To trace invisible labour is to find the material and action that account for it, and not only for its value. Otherwise, we would fall back into the issue of quantification. To trace invisible labour is to find a material that can engage with the affective relation surrounding the labour, a material that can understand/experience the invisibility rather than represent it. In both Gojak and Newby's work as explained before, the materials experience and embody the invisibility and do not opt to only represent it abstractly.

The cinematography and the script in Alfonso Cuarón's Roma (2018) explores the problem of invisible domestic labour of an Indigenous Mexican maid. There are other political dimensions to the work in relation to Indigenous language and matriarchy. In Roma, water as a material plays an active relation with the protagonist. She directs it through sweeping it at home and it borders on commanding her in the wavy seascape.

I am focusing on the appearance of water as a material tying the body with the seascape and domestic work. Alfonso Cuarón uses the water's materiality as a folding device between the domesticated restricted environment and the outside seascape. The black and white movie highlights water in its fluidity as a symbol of risk and rescue for the Indigenous maid. The opening scene starts with the task of sweeping water on the ground to clean the floor. Yet, to her male master, her labour is invisible. In the middle of the movie, her unwanted pregnancy ends with her water breaking and a dead embryo. One of the movie's final scenes includes her rescuing the children of her master. She hangs onto the shore despite the water's force. The water creates a triangular relation between the body, invisible labour, and the seascape. Note here the possible similarity (and differences) with how the thread operates in Gojak's work as a folding device to create an embodied measure of distance and the spinning movement of the hand.

By creating correspondences among materials, the body, and invisible tasks, artworks counter abstraction, standardized value, and the dematerialization of the economy. The matrix of time-space is replaced by the matrix time-body-material. The key examples chosen - Cecilia Vicuña's Symbiosis, Ritual Battle (2015), Mira Gojak's Distant measures (2016), Kate Newby's A rock in the pocket (2018), and Alfonso Cuarón's Roma (2018) - have dramatically different aesthetics and materials. Yet, I argue that they are possible forms of "attending to" materials interacting with the body, in particular the hand. The artists have set themselves tasks that respond to the qualities of the material they are engaging with. The repeated actions create multiple rhythmic gestures. Actions such as folding, pushing, incorporating onto, or wrapping are suggestive of tasks aligned with the type of material. The cyclicality hovers between the repeated action and an individuated gesture. I have argued that rematerialization in art through care and attention is a "reparative" process that does not expose explicitly the economic system but highlights alternative possibilities. The different artworks thus share an im-material poetry precisely coming from with-in-materials. 


\section{References}

Ahmed, Sara, 'Affective Economies', Social Text, 22 (2004), 117-39

Alÿs, Francis, 'When Faith Moves Mountains', Tate, 2002, https://www.tate.org.uk/whats-on/tatemodern/exhibition/francis-alys/francis-alys-story-deception-room-guide/francis-alys-3

Amiralay, Omar, 'A Plate of Sardines', UbuWeb Film \& Video, 1997. $<$ http://www.ubu.com/film/amiralay.html>

Berardi, Franco 'Bifo', 'The Uprising On Poetry and Finance', Semiotext(e) Intervention Series, 2012

'Commensurate | Origin and Meaning of Commensurate by Online Etymology Dictionary', Etymonline $<$ https://www.etymonline.com/word/commensurate>

Cuarón, Alfonso, Roma (Mexico and USA: Espectáculos Fílmicos El Coyúl (Mexico), Netflix (USA), 2018) $<$ https://www.imdb.com/title/tt6155172/>

Faietti, Marzia, and Gerhard Wolf, eds., The Power of Line : Linea III (Kunsthistorisches Institut in Florenz, Max-Planck-Institut.: Hirmer Publishers, 2015)

Green, Tamsin, 'Mira Gojak: Distant Measures', Eyeline Contemporary Visual Arts, 2018 <https://www.eyelinepublishing.com/eyeline-86/review/mira-gojak-distant-measures>

Imperial War Museum, 'Palestine Police', Colonialfilm, 1946. <http://www.colonialfilm.org.uk/node/6717> Ingold, Tim, The Life of Lines (London, New York: Taylor \& Francis Group, 2015)

, 'The Temporality of the Landscape', World Archeology, 25 (1993), 152-74

Lippard, Lucy R., Six Years: The Dematerialization of the Art Object from 1966 to 1972 (California, US; London, England: University of California Press, 2001, first published 1973)

Mangan, Nicholas, Limits to Growth (Vimeo; KW Institute for Contemporary Art, 2017) $<$ https://vimeo.com/220428594>

Mangan, Nicholas; Charlotte, Day; Aileen, Burns; Kris Gruijthuijsen and Johan. Lundh, eds. Nicholas Mangan : Limits to Growth (Sternberg Press, 2016)

Massumi, Brian, 99 Theses on the Revaluation of Value : A Postcapitalist Manifesto (University of Minnesota Press, 2018)

Molderings, Herbert, Duchamp and the Aesthetics of Chance, translated by John Brogden (New York Chichester, West Sussex: Columbia University Press, 2010)

Newby, Kate, 'A Rock in This Pocket', Sydney Biennale, 2018. $<$ https://www.biennaleofsydney.art/artists/kate-newby/>

O'Reilly, Rachel, 'Dematerializations of the Land / Water Object', E-Flux Journal, 2018

Schmandt-Besserat, Denise., How Writing Came About (University of Texas Press, 1996)

Scott, James C., Against the Grain : A Deep History of the Earliest States (New Haven and London: Yale University Press, 2017)

Sedgwick, Eve Kosofsky, Touching Feeling : Affect, Pedagogy, Performativity (Duke University Press, 2003)

Stiegler, Bernard, Technics and Time, 1, The Fault of Epimetheus, ed. by Richard Beardsworth and George Collins (translators), (Stanford California: Stanford University Press, 1998)

Vicuña, Cecilia, and Meredith Root-Bernstein, 'Symbiosis, Ritual Battle', (Video) (Kunsthal Aarhus, Denmark, 2015) <https://vimeo.com/138162864>

Warner, Michael. 'Uncritical Reading', Polemic : Critical or Uncritical, edited by Jane Gallop, Routledge, 2004. 